\title{
Discussion on construction scheme of aqueduct structure repair and water stop belt replacement in South-to-North Water Diversion project
}

\author{
Kang $\mathrm{Jao}^{1}$, Jian $\mathrm{Li}^{1}$, Jianshen Liu ${ }^{1}$, Zhiyong Zhou ${ }^{2,3,{ }^{*}}$, and Haihua Cheng ${ }^{3}$ \\ 1. Central Route Construction Management Bureau of South to North Water Transfer Project, Beijing 100053, China) \\ 2. Engineering Research Center of Building Inspection and Reinforcement, Ministry of Education, Wuhan University, Wuhan, Hubei \\ 430072, China \\ 3. WuDa Jucheng Structure Co., Ltd., Wuhan, Hubei 430223, China
}

\begin{abstract}
Taking Shahe and Dalang River aqueducts as an example, this paper introduces a movable and reusable waterproof device for aqueduct construction, which is suitable for construction scheme of structure repair and waterstop belt replacement for large-scale water delivery aqueduct of Shahe River and Dalang River in South-to-North Water Diversion Project. It aims to solve structural damage and waterstop belt leakage of the aqueducts of Shahe River and Dalang River in the South-to-North Water Diversion Project, realizing the aqueduct construction with uninterrupted water supply, and structure repair and waterstop belt replacement in the waterless environment separated by watertight device in the aqueduct construction.
\end{abstract}

\section{Introduction}

Shahe Aqueduct Project of the middle route of the South-to-North Water Diversion Project is located in Lushan County, Pingdingshan City, Henan Province, China. The $1,410 \mathrm{~m}$ beam-type aqueduct project in total length stretches across the Shahe River with $720 \mathrm{~m}$ span length. The body structure of the aqueduct is featured with U-shaped structure of prestressed reinforced concrete $^{[1]}$, complex space force of the body ${ }^{[2]}$, and extreme difficulty in construction, making its multiple engineering indicators top among others and rank "World's Top 1 Aqueduct". Shape of aqueduct body: 9m high, $9.3 \mathrm{~m}$ wide, $8 \mathrm{~m}$ diameter in internal emptiness of aqueduct depth, clear height of $8.07 \mathrm{~m}$, each aqueduct body of $1200 \mathrm{~T}$, and single span with four aqueducts. The structure section of single aqueduct is shown in Figure 1. In middle route of South-to-North Water Diversion Project, the aqueduct is an integral part of water delivery. Since the aqueduct has been reinforced concrete U-type aqueduct structure, the joints need to be installed with waterstop belts of rubber material. The material performance of waterstop belts changes under the influence of temperature in the process of service. Major changes in poor hardness, brittleness, sealing performance will lead to aqueduct leakage ${ }^{[3]}$.

\footnotetext{
Corresponding author: 124411319@qq.com
}

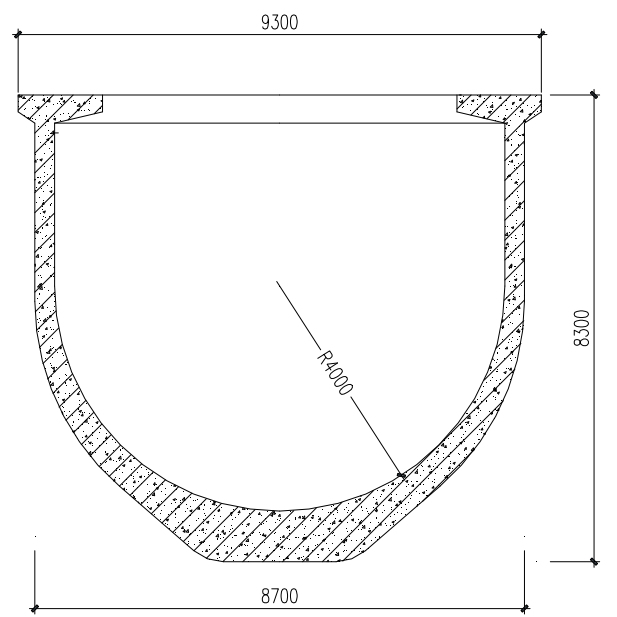

Fig. 1. Cross section of aqueduct.

At present, the replacement and repair treatment scheme for the waterstop belt is to close the upper and lower gates of the whole aqueducts, or close the upper and lower gate of a certain aqueduct, and then pump out the water in the aqueduct, forming a dry working environment to repair the aqueduct structure or replace the waterstop belts. This scheme of drainage has the defect of large pump output, low construction efficiency, long construction period and high cost. At the same time, this method needs to construct under the condition of completely or partially cutting off water supply, which will have a serious impact on water delivery in the middle route of the South-to-North Water Diversion 
Project. With the use of watertight device in the structure repair or waterstop belt replacement scheme, the construction can be carried out under the condition of uninterrupted water supply, which will greatly simplify the entire repair process, improve efficiency, ensure the rapid recovery of aqueduct service, and bring significant economic and social benefits.

\section{Key Technologies and Solutions}

The construction scheme of structure repair and water stop belt replacement proposed in this paper mainly includes the main body of the special steel structure construction separator device for aqueduct, water pressure system and hydraulic system of rotary gate.

\section{1 main body of the special steel structure construction separator device for aqueduct}
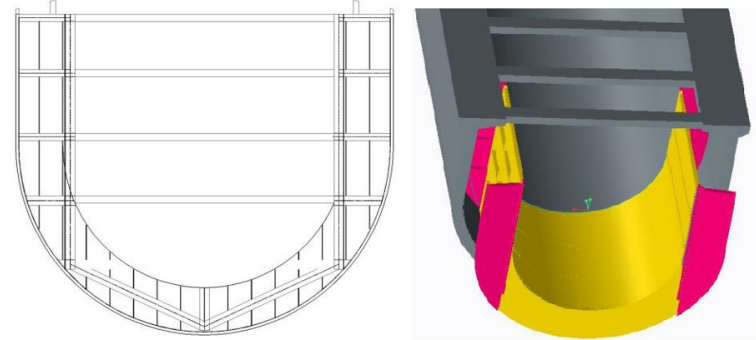

Fig 2 Main body of watertight device for special steel structure construction for aqueducts.

The main body of watertight device for special steel structure construction for aqueducts proposed in this scheme (as shown in Fig. 2) is used to inspect the aqueduct structure or replace the waterstop belt under the condition of water supply. The main body of the watertight device for special steel structure construction for aqueducts is composed of cofferdam steel structure, rotary gate and sealing assembly. With the steel structure support framework, the cofferdam steel structure except the three sides exposed to inner surface of the aqueduct will be welded on the steel structure frame by steel plates to ensure the sealing performance. The hinge joints of rotary gate are installed on four corners of the of cofferdam steel structure. When the watertight device for aqueduct is installed in the appropriate position, the rotary gate revolves at a certain angle and extrudes the sealing rubber plate pasted on the surface of the steel structure door of the cofferdam to form the watertight gate. The sealing assembly is composed of rubber plate, high-pressure water hose for sealing and steel sealing groove. The contact surface between the inner wall of the aqueduct and the cofferdam should be sealed to prevent water, as a result, the special sealing structure has been designed for the purpose. One side of the high-pressure water hose for sealing is pasted with a special adhesive in the steel pipe groove welded on the steel structure of the construction watertight device. And the other side is pasted on the rubber plate of proper hardness that fits into the inner wall of aqueduct. When pressurized water is injected into the high-pressure water hose for sealing, the hose will expand into a cylindrical shape, resulting in the extrusion of the steel tube groove and the rubber plate. The deformation of the rubber plate will result in the extrusion of the inner wall surface of the aqueduct for one side and the extrusion of the steel tube groove to form sealing for the other side. The concave surface of the steel pipe groove is bonded with the high-pressure water hose for sealing, and the other side is continuously welded to the cofferdam steel structure to form sealing.

\subsection{Water pressure system}

The water pressure system (as shown in Fig. 3) is used to inject high pressure water into the high-pressure soft water pipe for sealing in the main body of the the special steel structure construction separator device for aqueduct, so that the high-pressure soft water pipe for sealing squeezes the rubber plate in contact with the steel

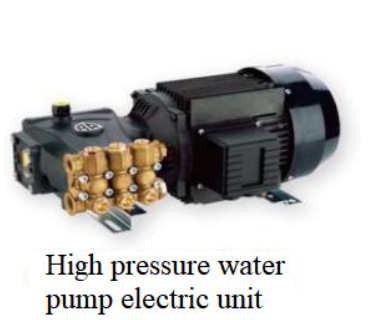

pump electric unit

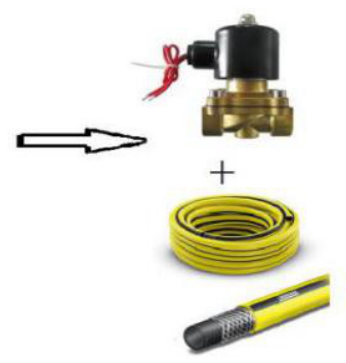

Water valves and pipes
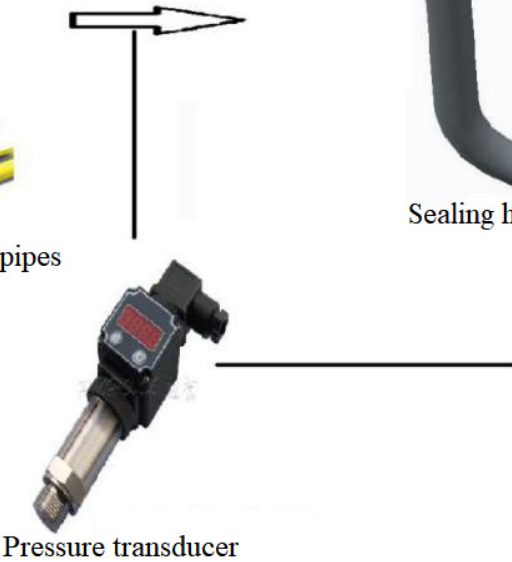

Pressure transducer

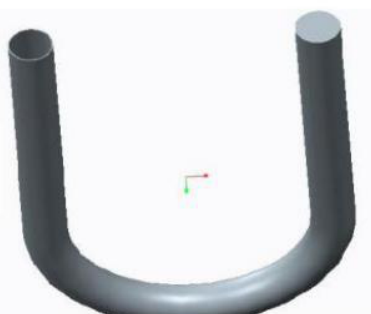

Sealing high pressure water pipes

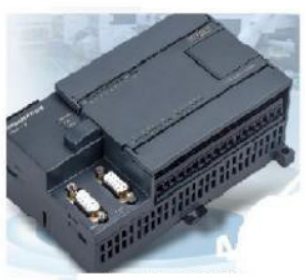

Electric control system

Fig. 3 water pressure system. 
sealing groove and the inner surface of the aqueduct to form an extrusion pressure seal. The water pressure system is the key part of the scheme, which is directly related to the water isolation effect of the construction water isolation device. The water pressure system consists of three parts: high pressure water pump electric unit, water valve and pipeline, and electric control system. The system needs to ensure that the water pressure in the high pressure soft water pipe used for sealing fluctuates in a certain range during construction. Only in this way can the extrusion pressure of the high-pressure soft water pipe used for sealing be guaranteed to be effective for a long time, so as to achieve the long-term sealing and water insulation effect of the cofferdam. High pressure water pump electric unit output high pressure water, high pressure water through the water valve and pipeline injected into the seal with high pressure water hose, pipe set pressure sensor. High pressure water pressure is transmitted through the pressure sensor to the monitoring and control system, monitoring and control system in water conservation pressure control, ensure sealing with high-pressure soft water pipe water pressure constant: low pressure filling water, regulated water, high pressure drain, this belongs to a kind of fuzzy PID control based on PLC and constant pressure water supply system design ${ }^{[4]}$.

\subsection{Rotary gate hydraulic system}

The hydraulic system of rotary gate is used to provide mechanical opening and closing power and closing pressure keeping for the rotary gate in the main body of the special steel structure construction separator device for aqueduct. The system has two functions: first, turn to the big and heavy aqueduct special steel structure construction separator device immersed in water, after loading aqueduct body subject to close the gate, not only to overcome frictional resistance, still can the water resistance, required torque is very large, so close the gate plate cylinder thrust hydraulic system can meet the demand. Second, provide the force needed to extrude the sealing rubber plate on the surface of the door seam to form a seal.Rotary gate hydraulic system consists of three parts: hydraulic system pump station system, turnstile cylinder, hydraulic electronic control system. The hydraulic pump station system (as shown in Figure 4) is composed of hydraulic pump, motor, fuel tank, valve, pipe joint and accessories ${ }^{[5]}$. The turnstile cylinder is the actuating element that provides the torque to turn the gate and enhances the extrusion pressure of the seal. Hydraulic electronic control system has two major working conditions. First, the oil cylinder action control. It controls the work execution of the hydraulic pump station system and indirectly controls the telescopic action of the cylinder. Second, holding pressure. Keep the sealing rubber plate on the surface of the extrusion door seam to form the sealing force required to ensure low pressure oil replenishing, stable pressure stop oil, high pressure discharge. In this way, according to the construction time sequence, the system selects the appropriate process.

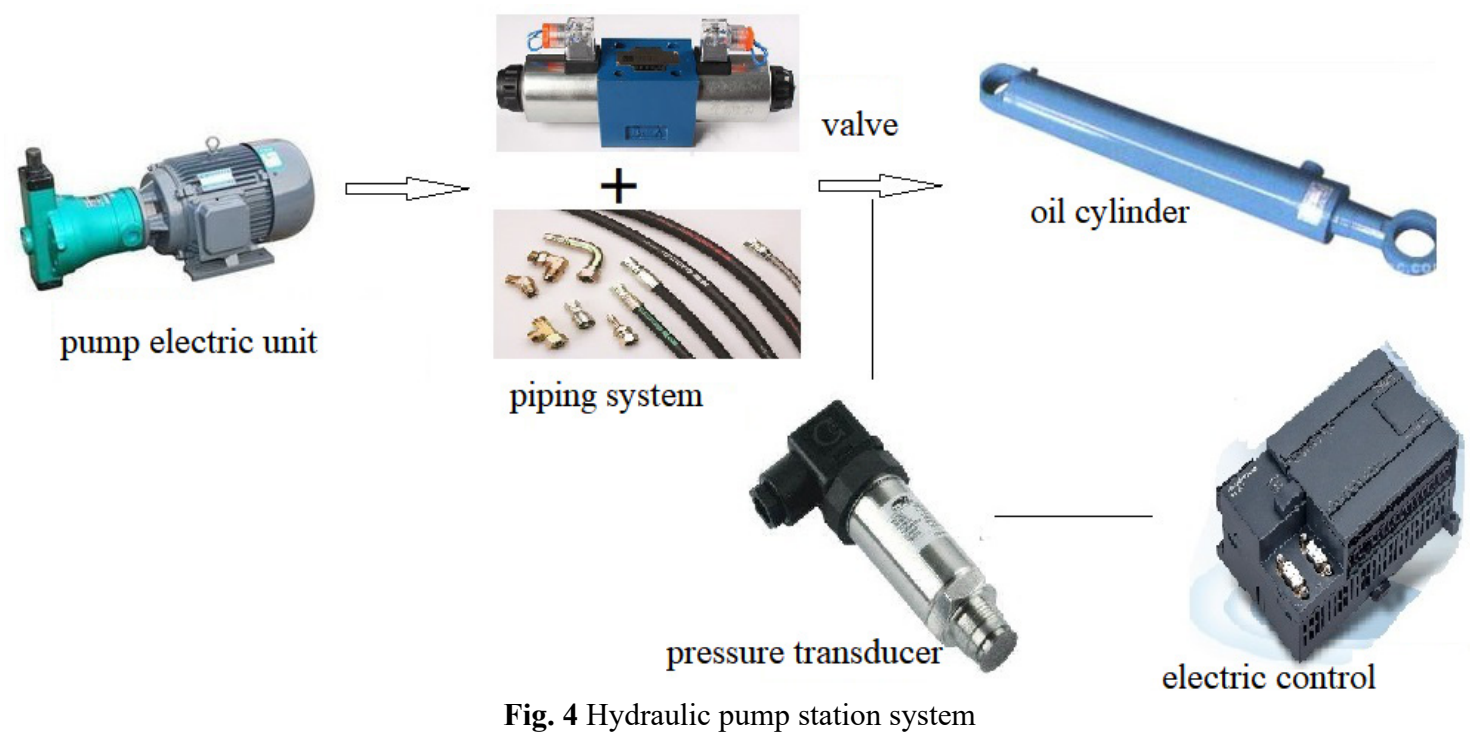

\section{Improvement scheme}

In order to improve the installation and disassembly efficiency of the device, the construction device can be designed in the form of construction vehicles. The vehicle has the following functions: first, has the lift and put down the aqueduct special steel structure construction water separator main body of the manipulator, can be installed on the frame of the mechanical arm, the vehicle into the aqueduct appropriate position, the main body of the structure into the aqueduct, when the construction is over, the main structure lifted. Second, water pressure system. Third, turn the hydraulic system of the gate. Fourth, the driving mechanism can ensure that the whole device moves on the aqueduct. 


\section{Summary}

This paper introduces a construction scheme of a special construction separator device for aqueduct, which is used for structural repair and water stop belt replacement. Taking Shahe aqueduct as an example, the design objective, working principle and preliminary experimental results of the construction scheme are introduced.

The scheme solves the problems of water seepage and leakage caused by the aging and damage of the water belt during the service process of the large-scale aqueduct in the South-to-North Water Diversion Project, and it can timely and flexibly repair and replace the water stop belt, so as to realize the continuous service of water in the aqueduct.

\section{Acknowledgement}

This work was financially supported by the National Key R\&D Program of China (project No. 2017YFC0405003).

\section{reference}

1. Chunzhi Yang. The general layout and structure selection of Shahe aqueduct project. South-to-North Water Diversion and Water Science and Technology, 2015, (8) 116-118.

2. YongminYang, Zepeng Chen, Junlu Zhang, Xinlong Yin. Influence of engineering conditions on aging of aqueduct water seal rubber water stop belt. Guangdong Water Resources and Hydropower,2014, (2) 15-19.

3. Yuanjun Zhai, Taishan Zhu,Guangwei Feng .Research and application of key technologies of Shahe aqueduct in the middle route of South-to-North Water Diversion Project. Yangtze River, 2013, 44(16):1-6.

4. Linghong Sun, feng Xue. Constant pressure water supply system design based on PLC and fuzzy PID control. Automation and Instrumentation, Vol.6, $2010: 35-36,39$.

5. Hongjia Zhang et al.Hydraulic and pneumatic transmission. China Machine Press,2001.06 